\title{
Guest Editorial Foreword to the Special Issue of the XII Symposium on Virtual and Augmented Reality
}

The special issue of the JIS (SBC Journal on 3D Interactive Systems) acknowledging the best papers of the XII Symposium on Virtual and Augmented Reality (SVR 2010) was an important opportunity to present excellent papers in the Virtual and Augmented Reality field. The SVR is for more than 12 years the most important event on Virtual and Augmented Reality in Brazil, which is being conduct by academic professionals members of the Brazilian Computer Society (SBC) that is supporting the conference for so many years.

Since this is the first special issue of JIS, we had selected papers to be included in the journal that fits the expectations of the readers. These papers were selected among the 10 best papers presented at the SVR 2010, and they come from different sub-areas of the Virtual and Augmented Reality.

The development introduced in the papers present important new proposals and algorithms that might be used by several readers of the journal.

The paper Exploring the Design of Transitional Hybrid User Interfaces authored by Daniela Trevisan, Felipe Carvalho, Alberto Raposo, Carla Freitas and Luciana Nedel, is about a discussion on how hybrid user interfaces should be managed in order to improve the feeling of immersion of the user in a virtual reality system.

The second paper Expression Cloning Based on Anthropometric Proportions and Deformations by Motion of Spherical Influence Zones authored by Roberto C. Vieira, Creto Augusto Vidal, and Joaquim B. Cavalcante-Neto presented methods of mapping human facial expressions to virtual characters. This works was based on anthropometric proportions and geometric manipulations by moving influence zones of model with similar characteristics.

The third paper Extending Brazilian DTV Middleware to Incorporate $3 D$ Technologies authored by Daniel F. L. Souza, Liliane S. Machado, Tatiana A. Tavares explains how properly support for 3D content can be integrated on the new Brazilian Digital Television. The paper presents strategies and examples to prove their proposal.

We would like to thank all the authors of this process that had to extend and adapted their papers as requested by both the submission and the reviewing process.

Judith Kelner (UFPE)

Luciano Pereira Soares (PUC-Rio)

Guest Editors

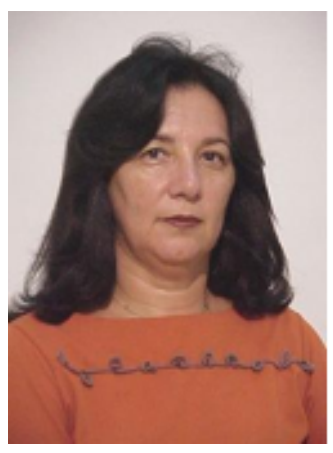

Judith Kelner received a First Degree in Civil Engineering (76) at the Federal University of Pernambuco (UFPE), Brazil and a Ph.D. at University of Kent at Canterbury, England (93). From 79-93, she worked as a lecturer at the Computer Science Department at UFPE. She has been working as a senior lecturer at the Computer Science Department at UFPE since 93. Since 97 she acts as the head of the Computer Science Department at UFPE and member of the board directors of FADE-UFPE (University Development Foundation), Recife and Vice-President of CESAR (Recife Center for Advanced Studies and Systems), Recife. Her research interests include programming languages, programming environments, multimedia applications, virtual reality and augmented reality.

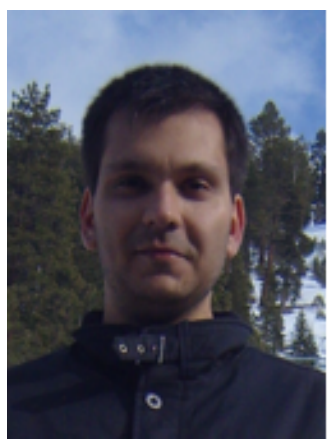

Luciano Pereira Soares holds a $\mathrm{PhD}$ in Electrical Engineering from Polytechnic School, University of São Paulo in Brazil. He was a postdoctoral research at IST, Instituto Superior Técnico in Portugal, INRIA, Institut $\mathrm{Na}-$ tional de Recherche en Informatique et en Automatique in France and ISCTE, Instituto Superior de Ciências do Trabalho e da Empresa in Portugal. His research interests include, immersive multiprojection systems, real-time 3D computer graphics and cluster computing. He is currently a researcher at the Tecgraf, Computer Graphics Technology Group in PUC-Rio working in several projects with Petrobras. He worked as support engineer at Silicon Graphics, application engineer at Alias-Wavefront and as project manager at the Integrated Systems Laboratory. 